\title{
Relationship between Baseline White Blood Cell and C-Reactive Protein with Mortality in Patients with Spontaneous Intracerebral Hemorrhage
}

\author{
${ }^{1}$ Neurocritical Care Unit, Sanatorio Pasteur, Catamarca, Argentina \\ ${ }^{2}$ Neurological Section, SMDN-Center for Cardiovascular Medicine and Cerebrovascular Disease Prevention, Sulmona (AQ) Italy \\ ${ }^{3}$ Central Laboratory, Sanatorio Pasteur, Catamarca, Argentina \\ ${ }^{4}$ Central Laboratory, Hospital Municipal Leonidas Lucero, Bahia Blanca, Buenos Aires, Argentina \\ 5 Intensive Care Unit, Emergency Service, Hospital Municipal Leonidas Lucero, Bahia Blanca, Buenos Aires, Argentina \\ ${ }^{6}$ Internal Medicine, Hospital Municipal Leonidas Lucero, Bahia Blanca, Buenos Aires, Argentina \\ ${ }^{7}$ Neurological Service, San Camillo de'Lellis General Hospital, Rieti, Italy
}

Daniel Agustin Godoy ${ }^{1 *}$, Francesca Papa ${ }^{2}$, Veronica Campi ${ }^{3}$, Marta del Valle ${ }^{4}$, Gustavo Piñero ${ }^{5}$, Matias Mirofsky ${ }^{6}$ and Mario Di Napoli,7*

\begin{abstract}
Background: Inflammation has been shown to play a role in animal models of intracerebral hemorrhage, but actually its role in predicting outcome in spontaneous intracerebral hemorrhage $(\mathrm{sICH})$ is not clear because of the lack of evidence. This study was designed to determine the relationship between baseline white blood cell (WBC) count and clinical outcomes in patients with $\mathrm{SICH}$ and to see if WBC count was a significant predictor of outcomes independent of other inflammatory biomarkers such as C-reactive protein (CRP) a well defined prognostic marker in ischemic stroke.

Methods: We evaluated the relationship between baseline WBC count, other baseline variables and biomarkers, neuroradiological findings, and clinical outcomes in 175 consecutive patients with a well-defined diagnosis of sICH admitted into 24 hours in 3 primary referred centers and included in a prospective observational follow-up registry.

Results: Higher baseline wbc counts were associated with hematoma volume at admission $(p<0.0001)$ as well as a greater sich severity $(p=0.0016)$ assessed by glasgow coma scale. a higher baseline wbc count was predictive of higher 30 -day mortality, ranging from $10.42 \%$ among patients with the lowest wbc count quartile to 66.7 among patients with the highest wbc count quartile $\left(p=<0.0001, \chi^{2}\right.$ for trend). however, in a multivariable proportional hazards model, wbc count was unable to confirm its predictive prognostic value when adjusted for possible confounding variables and crp concentration quartiles [hazards ratios (hr) $1.2395 \%$ confidence intervals (ci) 0.41-3.68, $p=0.7079$ ] while patients with the highest crp concentrations at admission showed a significantly higher risk of 30-day death ( $\mathrm{hr} 2.83,95 \% \mathrm{ci}$ 1.14-7.05, $p=0.0254)$ although, crp levels were only lightly associated with stroke severity $(p=0.0747)$.

Conclusions: In patients with $\mathrm{SICH}$, the WBC count was associated with 30-day high mortality rates although, this association reversed when other confounding variables were taken in account suggesting only a role of surrogate biomarker of sICH severity. CRP concentrations appeared more effective in predicting prognosis although its predictive power is limited.
\end{abstract}

Keywords: Intracerebral hemorrhage; White blood cell; Leukocyte; C-reactive protein; Prognosis

Abbreviations and Acronyms: 95\% Cl: 95\% Confidence Intervals; AMI: Acute Myocardial Infarction; APACHE II: Acute Physiology And Chronic Health Evaluation II; CRP: C-reactive Protein; DIC: Disseminated Intravascular Coagulation; GCS: Glasgow Coma Scale; GOS: Glasgow Outcome Scale; HR: Hazard Ratios; oICH: Hemphill's ICH Score; sICH: Spontaneous Intracerebral Hemorrhage; WBC: White Blood Cell

\section{Introduction}

Spontaneous intracerebral hemorrhage (sICH), defined as spontaneous bleeding into the brain, accounts for $10 \%$ to $20 \%$ of all strokes [1]. sICH is a devastating clinical event without effective therapies despite progressing in medical knowledge [1-4] with poor outcome[5]. Compared with ischemic stroke and subarachnoid hemorrhage, victims of sICH suffer higher mortality and are left with more severe deficits [3].

Existing contemporary data collected from preclinical and clinical studies indicates that inflammatory processes are involved in sICH [6] and in the progression of sICH-induced brain injury [6,7]. Several prospective studies have been indicated that brain injury secondary to a $\mathrm{sICH}$ is characterized by acute local inflammation
[7-9] and changes in levels of inflammatory cytokines in body fluids of human patients [10-13]. Elevated levels of inflammatory markers after sICH predict worse prognosis, [14] perihematoma brain edema, [10] early neurological deterioration, [12] and early growth of sICH [11]. Previous clinical studies have provided evidence that supports the role of leukocytes (WBC) in sICH. High WBC count has been reported to be one of the independent predictors of early neurologic

*Corresponding author: Dr. Daniel Agustin Godoy, MD. Neurocritical Care Unit Sanatorio Pasteur. Chacabuco 747, San Fernando del Valle de Catamarca, K 4700 - Argentina,Tel: + 543833 432000/6; E-mail: dagodoytorres@yahoo.com.ar

Dr. Mario Di Napoli, MD NeurologicạlSection, SMDN-Center for Cardiovascula Medicine andCerebrovascularDiseasePrevention, Via Trento, 41 67039-Sulmona (AQ) Italy, Tel: +39.(0)864.52716; Fax: +39.(0)864.52716; E-mail: mariodinapoli@ katamail.com

Received August 23, 2010; Accepted October 21, 2010; Published October 23 2010

Citation: Godoy DA, Papa F, Campi V, del Valle M, Piñero G, et al. (2010) Relationship between Baseline White Blood Cell and C-Reactive Protein with Mortality in Patients with Spontaneous Intracerebral Hemorrhage. J Neurol Neurophysiol 1:104. doi:10.4172/2155-9562.1000104

Copyright: (c) 2010 Godoy DA, et al. This is an open-access article distributed under the terms of the Creative Commons Attribution License, which permits unrestricted use, distribution, and reproduction in any medium, provided the original author and source are credited. 
deterioration in sICH [11,12]. Another of the most promising of these inflammatory markers is C-reactive protein (CRP), a biomarker of inflammation that has been shown to predict prognosis in ischemic stroke after adjustment for all major prognostic components [15]. Unfortunately, previous studies have only marginally evaluated CRP as a prognostic marker after sICH with contrasting results $[14,16]$.This has led to a renewed interest in the study of inflammation markers, including CRP and WBC count, in sICH. Therefore, we evaluated the clinical utility of 2 selected inflammatory markers, WBC and CRP that can be easily determined during the acute phase of sICH as potential outcome predictors in sICH patients.

\section{Materials and Methods \\ Selection of study population}

We prospectively recruited all consenting patients admitted to 3 Intensive Care Units from Buenos Aires State in Argentina, with a diagnosis of sICH within 24 hours after stroke onset, between November 1, 2003 and October 31, 2006. sICH was defined as the sudden and spontaneous intraparenchymal bleeding confirmed by head CT scan with or without intraventricular extension. These primary referred centers have no specific selection criteria for the admission of sICH patients. All participants gave consent directly or through their legal representatives. Our institutional committee approved the study. Admissions fulfilling one or more of the following criteria were excluded: pregnancy $(n=2)$, hemorrhage secondary to brain tumors $(n=10)$, trauma $(n=36)$, hemorrhagic transformation of cerebral infarct $(n=4)$, ruptured aneurysm or vascular malformation $(\mathrm{n}=27)$, first evaluation more than 24 hours after symptom onset $(n=15)$, referral from another hospital after diagnosis and initial evaluation $(n=13)$ and missing data due to very early death $(n=13)$. To avoid confounding factors in the determination of inflammatory markers, we also excluded patients with a history of acute or chronic infections ( $\leq 4$ weeks prior to $\mathrm{sICH}$ ) at admission, concurrent major renal or hepatic disease, cancer, chronic or acute inflammatory diseases, surgery or major trauma in the previous month and those with obvious signs and clinical evidence of acquired in-hospital infection $(n=62)$ (Figure 1). A detailed description of our study methodology has been published previously [17].

\section{Index evaluation}

All patients were screened according to a strict protocol consisting of a complete medical history, a full neurological examination, standardized blood tests, at least 1 and usually 2 CT scans of the brain [17]. Surgical criteria were established according to the algorithm of decision in force to authors' institutions based on the guidelines of Stroke Council of the American Heart Association [2] and European Stroke Initiative recommendations (Appendix I) [18]. The Glasgow Coma Scale (GCS) assessed initial stroke severity and determined after initial evaluation and resuscitation [19], while comorbidities were evaluated according to the Acute Physiology and Chronic Health Evaluation II (APACHE II) score guidelines [20]. sICH Severity was also classified according to original Hemphill's ICH score $(\mathrm{olCH})$ [21]. The following data were prospectively collected in a computerized database: age, sex, recognized risk factors for sICH (arterial hypertension, alcohol intake, smoking, diabetes mellitus, serum cholesterol levels, anticoagulant treatment), presence of comorbidities, glucose levels at admission and 72 hours after stroke onset, systolic, diastolic and pulse blood pressure (defined as systolic blood pressure minus diastolic blood pressure), GCS and oICH scores, and CT scan findings. All definitions and diagnostic criteria were previously reported $[22,23]$.

\section{Blood sampling and C-reactive protein assay}

All routine biochemistry, hematology and coagulation data were collected at the entry, within 24 hours after sICH onset. Standard techniques were used to measure routine laboratory panels. WBC counts were done with Coulter counter. Blood samples collected in EDTA were also assayed for CRP by use of a high-sensitivity immunoturbidimetric assay (Tina-quant CRP detection method; Roche Diagnostics) performed on a Modular D 914 analysis system (Mannheim, Germany) with a calibrator based upon the international calibrator CRM 470. The manufacturer claimed the detection limit to be $0.1 \mathrm{mg} / \mathrm{l}$ and the extended measuring range (with reruns) to be $0.1-240 \mathrm{mg} / \mathrm{l}$. The coefficient of variation ranged from $0.6 \%$ to $1.3 \%$ for the intra-assay precision and from $1.3 \%$ to $6 \%$ for the interassay reproducibility. Baseline WBC counts and CRP concentrations were available in all 175 patients. Laboratory workers were blinded to clinical information and quality control was maintained using standard procedures.

\section{Neuroradiological findings}

Investigators who read CT scans were blinded to clinical information and classified neuroradiological findings according to localization (supratentorial or infratentorial), site of sICH (basal ganglia, thalamic, lobar, pontine, or cerebellar), volume of hematoma, midline shift, intraventricular extension of hemorrhage, presence of hydrocephalus and determined in the initial CT scan. sICH hematoma volume was measured with the use of the $A B C / 2$ method, in which $\mathrm{A}$ is the greatest diameter on the largest hemorrhage slice, $\mathrm{B}$ is the diameter perpendicular to $A$ and $C$ is the approximate number of axial slices with hemorrhage multiplied by the slice thickness [24].Midline shift was determined by measuring the displacement of the septum pellucidum across midline, using as reference a perpendicular line connecting the anterior and posterior insertions of the falx cerebri at the level of the lateral ventricles and third ventricle [25]. The presence or absence of IVH was also noted on initial head CT and graded according to Graeb scale [26]. Hydrocephalus was determined with the Diringer's method [27].

\section{Outcome measures and follow-up}

The primary end-points, considered in this analysis were 30-day global mortality after sICH and 30-day functional outcome. Global mortality included the combination of any neurological and nonneurological death. Neurological death was defined as death occurring as a direct consequence of the qualifying $\mathrm{sICH}$ or of a new bleeding in the absence of other intervening causes. Non-neurological death included all other, vascular and non vascular deaths, not included in the neurological death. Unknown death was diagnosed in the presence of underlying pathology not otherwise specified. 30-day functional outcome was assessed using the Glasgow Outcome Scale (GOS), categorized in good (GOS, 4-5) and worse (GOS, 2-3) functional outcome for statistical assessments [28]. All outcome events were validated by a study physician. For patients in whom 30-day outcome was not available from medical records $(n=2)$, follow-up data were obtained from follow-up visits. We were able to obtain current information on all included patients. All definitions and outcome diagnostic criteria were previously reported and validated by a study physician $[17,22,29]$. The evaluators were blinded to information regarding inflammation markers that were not used to modify current treatment both during in-hospital and follow-up period.

\section{Statistical analysis}

Significance for intergroup differences was assessed by use of the 
$\chi 2$-test, using Fisher-Freeman-Halton correction when appropriated, by unpaired t-test for continuous normally distributed, and MannWhitney U test for non-normally distributed variables. Continuous variables are described as mean \pm SD or median values with $25^{\text {th }}$ and $75^{\text {th }}$ percentiles, according to manner of distribution. Values for CRP and WBC count were log-transformed as needed for correlation analyses. Correlations between inflammatory marker values and other prognostic factors were also calculated. After examining the distributions, inflammatory marker values were categorized by quartiles for further analyses. Cumulative survival curves were calculated using the Kaplan-Meier method. Cox proportional hazard models were then constructed to estimate hazard ratios and $95 \%$ confidence intervals $(\mathrm{HR}, 95 \% \mathrm{Cl})$ for the effect of these markers on the independent risk of 30-day mortality. Unadjusted models and models adjusted for demographic characteristics (age and sex), risk factors (arterial hypertension, diabetes mellitus, smoking status and alcohol abuse) and stroke severity (assessed oICH score) were calculated. Interaction terms were included to satisfy assumptions of proportionality, and there was no evidence of overfitting or collinearity. Age (per 10-year increase), olCH scores (per 1-point increase), glucose concentration (per $1.0 \mathrm{mmol} / \mathrm{l}$ increase) and $\mathrm{sICH}$ hematoma volume (per $1 \mathrm{cc}$ increase) were entered into the Cox proportional hazard models as continuous variables. All the other variables were included as categorical dichotomized variables as previously described [17].

\section{Results}

During study period, 357 patients with clinical signs attributable to
sICH were identified. After a comprehensive evaluation 175 (103 men and 72 women; $\mathrm{m} / \mathrm{w}$ ratio: 1.43 ) patients were included in the present study, the remaining 182 patients $(51 \%)$ were excluded because they did not fulfill the inclusion criteria for the present study and (Figure 1). Baseline characteristics of patients such as demographic data, risk factor profile, clinical variables and radiological data from baseline CT scans are summarized in (Table 1).

\section{Laboratory findings}

Blood samples were drawn with a median time from sICH onset and admission of 120 minutes (25\% to $75 \%$ interquartile ranges, 55 to 330 minutes). The baseline $\mathrm{WBC}$ count ranged from 3.4 to $21.0 \times 10^{9} / \mathrm{l}$. The mean WBC count was $8.7 \pm 3.4 \times 10^{9} / 1$, the median was $8.0 \times 10^{9} / l$, and the $25^{\text {th }}$ and $75^{\text {th }}$ percentiles were 6.5 and 9.9 $\mathrm{x} 10^{9} /$, respectively. CRP had a skewed distribution, with median $9.0 \mathrm{mg} / \mathrm{l}(25 \%$ to $75 \%$ interquartile ranges, 5 to $17.1 \mathrm{mg} / \mathrm{l})$ and mean $16.0 \pm 18.14 \mathrm{mg} / \mathrm{l}$ values, respectively. WBC count and CRP were not correlated $\left(r^{2}=0.01, P=0.1518\right)$. WBC was strongly correlated with hematoma volume at admission $\left(\mathrm{r}^{2}=0.33, \mathrm{P}<0.0001\right)$ and marginally associated with blood glucose $\left(r^{2}=0.17, P=0.021\right)$, but CRP was not. WBC was strongly associated with sICH severity. The proportion of those with WBC count in the highest quartile increased markedly from mild $(11.0 \%, \mathrm{n}=11)$ to moderate $(26.8 \%, \mathrm{n}=15)$ to severe $\mathrm{sICH}$ $\left(52.6 \%, \mathrm{n}=10, \chi^{2}=21.35, \mathrm{P}=0.0016\right)$ assessed by GCS. The same results were also obtained using olCH score $[5.6 \%(n=5)$ vs $34.4 \%$ $(\mathrm{n}=22)$ vs $40.9 \%(\mathrm{n}=9) ; \chi^{2}=32.98, \mathrm{P}=<0.0001$, respectively]. WBC was also associated with history of alcohol abuse, with 17 (35.0\%) of non-abusers and 14 (35.0\%) of current abusers having WBC count

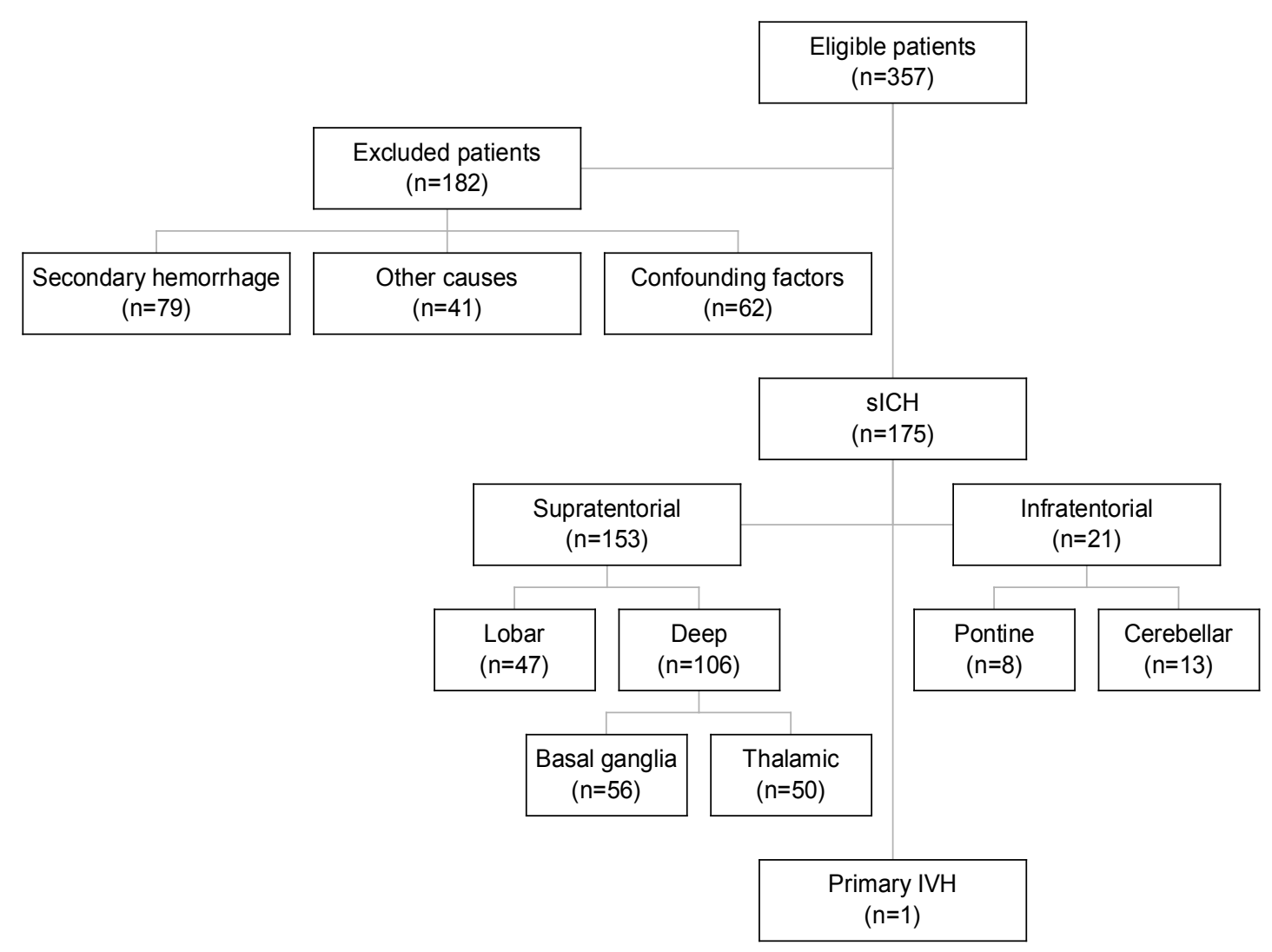

Figure 1: Study flow-chart. 
Citation: Godoy DA, Papa F, Campi V, del Valle M, Piñero G, et al. (2010) Relationship between Baseline White Blood Cell and C-Reactive Protein with Mortality in Patients with Spontaneous Intracerebral Hemorrhage. J Neurol Neurophysiol 1:104. doi:10.4172/2155-9562.1000104

Page 4 of 8

\begin{tabular}{|c|c|c|c|c|c|c|c|c|c|c|c|c|}
\hline \multirow{3}{*}{\begin{tabular}{|l|} 
\\
Age, y (SD) \\
\end{tabular}} & & & \multicolumn{4}{|c|}{ 30-day mortality } & \multirow{3}{*}{\begin{tabular}{|r|}
$P$ value \\
0.2930 \\
\end{tabular}} & \multicolumn{5}{|c|}{ 30-day outcome } \\
\hline & \multicolumn{2}{|c|}{$\begin{array}{l}\text { All Patients, } \\
\mathrm{n}=175\end{array}$} & \multicolumn{2}{|c|}{ No, $n=119$} & \multicolumn{2}{|c|}{ Yes, $n=56$} & & \multicolumn{2}{|c|}{$\begin{array}{l}\text { Better (GOS 4-5), } \\
n=78\end{array}$} & \multicolumn{2}{|c|}{ Worse (GOS 2-3), $n=41$} & \multirow{2}{*}{\begin{tabular}{|r|}
$P$ value \\
0.0139 \\
\end{tabular}} \\
\hline & 66.3 & $(11.8)$ & 65.7 & $(11.6)$ & 67.7 & $(12.3)$ & & 63.8 & $(10.1)$ & 69.2 & (13.4) & \\
\hline Male sex, $\mathrm{n}(\%)$ & 103 & $(58.9)$ & 69 & $(58.0)$ & 34 & $(60.7)$ & 0.7320 & 43 & $(55.1)$ & 26 & $(63.4)$ & 0.3841 \\
\hline \multicolumn{13}{|l|}{ Vascular risk factors } \\
\hline Arterial hypertension, $\mathrm{n}(\%)$ & 143 & (81.7) & 98 & $(82.3)$ & 45 & $(80.4)$ & 0.7512 & 63 & $(80.8)$ & 35 & (85.4) & 0.5319 \\
\hline Diabete mellitus, $\mathrm{n}(\%)$ & 50 & $(28.6)$ & 28 & (23.5) & 22 & $(39.3)$ & 0.0314 & 20 & $(25.6)$ & 8 & (19.5) & 0.4538 \\
\hline Alcohol abuse, $\mathrm{n}(\%)$ & 40 & $(22.9)$ & 24 & $(20.2)$ & 16 & $(28.6)$ & 0.0223 & 16 & $(20.5)$ & 8 & $(19.5)$ & 0.9923 \\
\hline Cigarette smoking, n (\%) & 52 & $(29.7)$ & 37 & $(31.1)$ & 15 & $(26.8)$ & 0.1586 & 16 & $(39.0)$ & 21 & $(26.9)$ & 0.3969 \\
\hline Hypercholesterolemia, n (\%) & 50 & $(28.6)$ & 32 & $(26.9)$ & 18 & $(32.1)$ & 0.2962 & 24 & $(30.8)$ & 8 & $(19.5)$ & 0.4185 \\
\hline \multicolumn{13}{|l|}{ Clinical characteristics } \\
\hline GCS score, median $\left(25^{\text {th }}-75^{\text {th }}\right)$ & 13 & $(9-15)$ & 14 & $(13-15)$ & 7 & $(4-10)$ & $<0.0001$ & 15 & $(14-15)$ & 12 & $(11-14)$ & $<0.0001$ \\
\hline olCH score, median $\left(25^{\text {th }}-75^{\text {th }}\right)$ & 1 & $(1-3)$ & 1 & $(0-2)$ & 3 & $(3-4)$ & $<0.0001$ & 1 & $(0-1)$ & 1 & $(1-3)$ & $<0.0001$ \\
\hline Pupillary abnormalities, ${ }^{*} \mathrm{n}(\%)$ & 29 & $(16.6)$ & 3 & $(2.5)$ & 26 & $(46.4)$ & $<0.0001$ & 1 & $(1.3)$ & 2 & $(4.9)$ & 0.2344 \\
\hline \multicolumn{13}{|l|}{ Radiological variables } \\
\hline Localization of the $\mathrm{SICH}, \mathrm{n}(\%)$ & & & & & & & 0.5039 & & & & & 0.0148 \\
\hline Basal ganglia & 56 & $(32.0)$ & 38 & (31.9) & 18 & $(32.1)$ & & 18 & $(23.1)$ & 20 & (48.8) & \\
\hline Thalamic & 13 & $(7.4)$ & 11 & $(9.2)$ & 2 & $(3.6)$ & & 9 & $(11.5)$ & 2 & $(4.9)$ & \\
\hline Lobar & 47 & $(26.9)$ & 32 & $(26.9)$ & 15 & $(26.8)$ & & 25 & $(32.1)$ & 7 & $(17.0)$ & \\
\hline Pontine & 50 & $(28.6)$ & 32 & $(26.9)$ & 18 & $(32.1)$ & & 20 & $(25.6)$ & 12 & (29.3) & \\
\hline Cerebellar & 8 & $(4.6)$ & 6 & $(5.0)$ & 2 & $(3.6)$ & & 6 & $(7.7)$ & 0 & - & \\
\hline Other & 1 & $(0.5)$ & 0 & - & 1 & $(1.8)$ & & - & - & - & - & \\
\hline Volume cc, median $\left(25^{\text {th }}-75^{\text {th }}\right)$ & 20 & $(9-40)$ & 15 & $(7-24)$ & 40 & $(21-70)$ & $<0.0001$ & 9.5 & $(6-16)$ & 22 & $(16-30)$ & $<0.0001$ \\
\hline Midline shift, $\mathrm{mm}$ & & & & & & & $<0.0001$ & & & & & 0.2194 \\
\hline $0-5$ & 141 & $(80.6)$ & 114 & (95.8) & 27 & $(48.2)$ & & 76 & $(97.4)$ & 38 & $(92.7)$ & \\
\hline $6-9$ & 19 & $(10.8)$ & 5 & $(4.2)$ & 14 & $(25.0)$ & & 2 & $(2.6)$ & 3 & $(7.3)$ & \\
\hline $10-14$ & 11 & (6.3) & 0 & - & 11 & (19.6) & & - & - & - & - & \\
\hline$>15$ & 4 & (2.3) & 0 & - & 4 & $(7.1)$ & & - & - & - & - & \\
\hline IVH & 83 & $(47.4)$ & 38 & (31.9) & 45 & $(80.4)$ & $<0.0001$ & 19 & $(24.4)$ & 19 & $(46.3)$ & 0.0145 \\
\hline Graeb's score, median $\left(25^{\text {th }}-75^{\text {th }}\right)$ & 4 & $(3-7)$ & 3 & $(2-5)$ & 6 & $(3-8)$ & 0.0012 & 3 & $(2-4)$ & 4 & $(3-7)$ & 0.0278 \\
\hline Hydrocephalus & 55 & $(31.4)$ & 20 & $(16.8)$ & 35 & $(62.5)$ & $<0.0001$ & 8 & $(10.3)$ & 12 & $(29.3)$ & 0.0084 \\
\hline \multicolumn{13}{|c|}{$\begin{array}{l}\text { Biochemistry and vital signs on hospital } \\
\text { arrival }\end{array}$} \\
\hline Plasma glucose, $\mathrm{mmol} / \mathrm{l}(\mathrm{SD})$ & 8.75 & $(4.13)$ & 7.62 & $(3.50)$ & 11.14 & $(4.36)$ & $<0.0001$ & 7.96 & $(3.98)$ & 7.02 & $(2.38)$ & 0.0600 \\
\hline WBC, $\times 10^{9} / I$ median $\left(25^{\text {th }}-75^{\text {th }}\right)$ & 8.0 & $(6.5-9.9)$ & 7.3 & $(5.7-8.8)$ & 9.9 & $\begin{array}{l}(8.7- \\
14.0)\end{array}$ & $<0.0001$ & 6.8 & $(5.7-8.7)$ & 7.6 & $(6.5-9.8)$ & 0.1034 \\
\hline CRP, mg/l median $\left(25^{\text {th }}-75^{\text {th }}\right)$ & 9.0 & $(5-17.1)$ & 8.0 & $\begin{array}{l}(5.0- \\
13.5)\end{array}$ & 10.6 & $\begin{array}{l}(6.5- \\
19.6)\end{array}$ & 0.0747 & 8.5 & $(5.0-19.0)$ & 7.8 & $(4.7-11.0)$ & 0.2308 \\
\hline Ipoxemia ${ }^{\dagger}(\%)$ & 31 & $(17.7)$ & 5 & $(4.2)$ & 26 & $(46.4)$ & $<0.0001$ & 0 & - & 5 & $(12.2)$ & 0.0016 \\
\hline $\mathrm{SBP}, \mathrm{mmHg}(\mathrm{SD})$ & 172 & $(40)$ & 175 & $(36)$ & 166 & $(48)$ & 0.2462 & 177 & $(35)$ & 172 & $(39)$ & 0.4275 \\
\hline $\mathrm{DBP}, \mathrm{mmHg}(\mathrm{SD})$ & 96 & $(22)$ & 98 & (21) & 94 & (24) & 0.3324 & 97 & (19) & 98 & $(24)$ & 0.8769 \\
\hline $\mathrm{PP}, \mathrm{mmHg}(\mathrm{SD})$ & 76 & $(25)$ & 77 & $(24)$ & 73 & $(27)$ & 0.3142 & 80 & $(23)$ & 73 & $(25)$ & 0.0763 \\
\hline \multicolumn{13}{|l|}{ Therapy } \\
\hline Surgery & 39 & $(22.3)$ & 19 & $(16.0)$ & 20 & $(35.7)$ & 0.0034 & 10 & (12.8) & 9 & $(21.9)$ & 0.1963 \\
\hline
\end{tabular}

GCS score indicates Glasgow Coma Scale score;ICH intracerebral hemorrhage; IVH intraventricular hemorrhage. *Pupillar abnormalities include pupillary inequality (anisocoria) or bilateral miosis and/or midirasis. †Prehospital hypoxemia includes cianosis, apnea or $\mathrm{SaO}_{2}<90 \mathrm{mmHg}$

Table 1: Baseline characteristics and potential baseline factors associated with 30-day mortality and 30-day outcome.

\begin{tabular}{|c|c|c|}
\hline Causes of death & $n$ & $(\%)$ \\
\hline Neurological death & 48 & $(85.7)$ \\
\hline Primary injury & 32 & \\
\hline Rebleeding & 13 & \\
\hline Cerebral oedema & 3 & \\
\hline Non Neurological & 8 & (14.3) \\
\hline ARDS & 1 & \\
\hline AMI & 2 & \\
\hline $\mathrm{DIC}$ & 1 & \\
\hline Ventricular arrhythmias & 1 & \\
\hline Pulmonary embolism & 2 & \\
\hline Cardiac tamponade & 1 & \\
\hline Total & 56 & \\
\hline
\end{tabular}

ARDS indicates Acute Respiratory Distress Syndrome, AMI, Acute Myocardial Infarction, DIC, Disseminated Intravascular Coagulation

Table 2: Causes of death after $\mathrm{sICH}$ in 175 patients

in the fourth quartile $(\mathrm{P}=0.0173)$. WBC count was not associated with other risk factors. Conversely, CRP levels were only lightly associated with stroke severity $(\mathrm{P}=0.0747)$. The proportion of those with CRP levels in the highest quartile among mild stroke patients
$(25.0 \%, n=25)$ did not differ significantly from those with moderate $(25.0, \mathrm{n}=14)$ or severe $(21.1 \%, \mathrm{n}=4)$ stroke $(\mathrm{P}=0.13)$. Proportions of patients with CRP levels in the highest quartile did not differ by age, sex, and vascular risk factors. 


\section{Relationship of WBC count and CRP concentrations to clinical outcomes}

30-day mortality rate was $32.2 \%(n=56), 48(85.7 \%)$ neurological and 8 non-neurological deaths. Causes of death are given in (Table 2). The baseline WBC count was higher in patients who died within 30 days $(\mathrm{P}<0.0001)$ but not $\mathrm{CRP}$ concentration at admission $(\mathrm{P}=0.0747)$ (Table 1). When analyzed as a categorical variable, higher baseline WBC count was predictive of higher 30-day mortality, ranging from $10.4 \%$ among patients with the lowest WBC count to 66.7 among patients with the highest WBC count $\left(\chi^{2}=31.29, \mathrm{P}=<0.0001, \chi^{2}\right.$ for trend) (Figure 2A). When stratified by baseline WBC count, event rates diverged over the first 2 weeks $(\mathrm{P}<0.0001$, log-rank test; $\mathrm{P}<0.0001, \chi^{2}$ for trend) and then remained roughly parallel (Figure 2B). Unadjusted and adjusted HR for the association of WBC and CRP with mortality across quartiles of these markers are presented in (Table 3). The cumulative mortality risk among those in the highest quartile of WBC was $4.21 \%$ (95\% CI $1.87-9.97 \%)$, compared to a risk of $0.24 \%$ (95\% CI $0.07 \%-0.67 \%)$ among those in the lowest quartile. Cumulative mortality risk among those in the highest quartile of CRP was $1.26 \%(95 \% \mathrm{Cl} 0.58 \%-2.65 \%)$, compared with a risk of $0.54 \%(95 \%$ CI 0.22-1.26\%) among those in the lowest quartile. To further explore the relationship between WBC count and CRP concentration with mortality across quartiles we stratified patients according to $\mathrm{sICH}$ volume. sICH volume was cathegorized using previously established cutoffs ( $<25 \mathrm{cc}, 25$ to $50 \mathrm{cc}, 51$ to $80 \mathrm{cc},>80 \mathrm{cc}$ ) correlated with outcome (Table 4) [30]. In patients with hematoma volume lower than

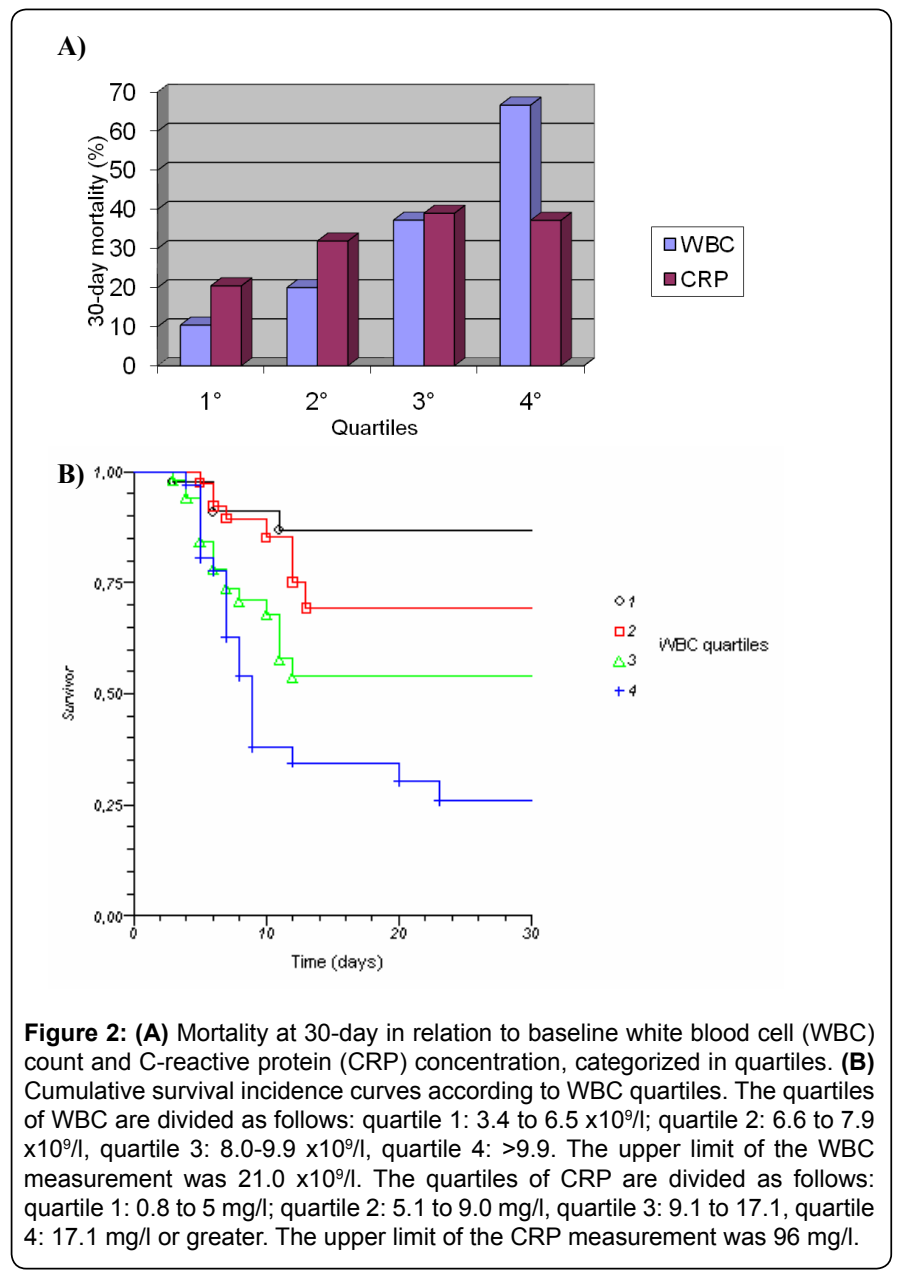

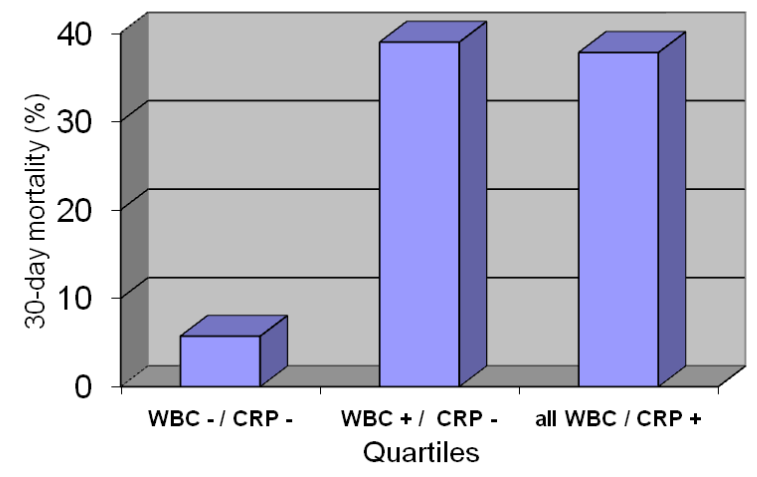

Figure 3: 30-day mortality in relation to both baseline white blood cell (WBC) count and C-reactive protEin (CRP) level, categorized as low WBC count $(\leq$ Quartile 1) plus low CRP level ( $\leq 15 \mathrm{mg} / \mathrm{l})$, high WBC count (> Quartile 1) plus low CRP level, and any WBC count plus high CRP level (>15 mg/l). The quartile 1 of WBC is equal to 3.4 to $6.5 \times 10^{9} / 1$.

$25 \mathrm{cc}$ and above $80 \mathrm{cc}$, WBC count at the entry showed a stronger significantly association with mortality rate than CRP concentration; conversely, in patients with hematoma volume between 25 to $50 \mathrm{cc}$ and between 50 to $80 \mathrm{cc}$, higher CRP concentration was associated with a higher 30-day mortality rate but not WBC count.

We also examined the relationship between WBC count and surgery, a decision at the discretion of the treating physician. The 30-day mortality rates across the WBC count categories were $9.5 \%$, $13.3 \%, 34.1 \%$ and $65.0 \%$ among patients who were not operated $(\mathrm{P}<0.0001)$ and $16.7 \%, 40 \%, 57.1 \%$ and $68.7 \%$ among patients who were operated $(\mathrm{P}=0.1424)$.

As an elevated WBC count may be a marker of inflammation similar to CRP, we further explored the relationship among WBC count, CRP and clinical outcomes. Patients were stratified by baseline CRP level using a previously established cutoff of $15 \mathrm{mg} / \mathrm{l}$ (Table 5) [22]. Among the 130 patients (74.3\%) who had a CRP level $\leq 15 \mathrm{mg} / \mathrm{l}$, WBC count remained a predictor of 30-day mortality. Patients with the lowest WBC count had a 30-day mortality of about $6 \%$, whereas patients with higher WBC count had a 30-day mortality of $26 \%$ to $68 \%$ $(\mathrm{P}<0.0001)$. Among the 45 patients $(25.7 \%)$ who had an elevated CRP level ( $>15 \mathrm{mg} / \mathrm{l})$, 30-day mortality was relatively high (23\% to $64 \%)$ and WBC count remained a predictor of 30-day mortality $(\mathrm{P}=0.0076)$. Therefore, patients were categorized into three groups according to their combined WBC and CRP status: 1 ) low WBC count (lower quartile, $\left.<6.5 \times 10^{9} / \mathrm{l}\right)$ plus low CRP level ( $\left.\leq 15 \mathrm{mg} / \mathrm{l}\right) ; 2$ ) high WBC count $\left(>6.5 \times 10^{9} /\right.$ l) plus low CRP level and 3$)$ any WBC count plus high CRP level $(>15 \mathrm{mg} / \mathrm{l})$. Using these two markers allowed us to risk stratify patients across an approximate sevenfold graded increase in 30-day mortality (Figure 3 ). Patients with both a low WBC count plus a low CRP level $(n=35)$ had a low mortality rate $(5.7 \%)$, patients with an elevated WBC count but a low CRP level $(n=95)$ and patients with any WBC count plus an elevated CRP level $(n=45)$ had a higher mortality rate $\left(63.8 \%\right.$ and $60.7 \%$, respectively; $\mathrm{P}=0.0045, \chi^{2}$ for trend).

In multivariable model after fully adjusting for demographics, risk factors, stroke severity and both inflammatory markers, those in the highest quartile of CRP, had more than twice the risk of death (adjusted HR 2.83, 95\% CI 1.14-7.05; $\mathrm{P}=0.0254$ ), while those in the highest WBC quartile were not more at increased mortality risk (adjusted HR 1.23, 95\% CI 0.41-3.68; $\mathrm{P}=0.7079$ ). olCH score alone (adjusted HR per point increase 3.14, 95\% CI 2.29-4.32, $\mathrm{P}<0.0001$ ) also predicted mortality. 
Citation: Godoy DA, Papa F, Campi V, del Valle M, Piñero G, et al. (2010) Relationship between Baseline White Blood Cell and C-Reactive Protein with Mortality in Patients with Spontaneous Intracerebral Hemorrhage. J Neurol Neurophysiol 1:104. doi:10.4172/2155-9562.1000104

Page 6 of 8

\begin{tabular}{|c|c|c|c|c|c|c|c|c|c|c|c|c|}
\hline \multirow[b]{3}{*}{ Outcome event } & \multicolumn{12}{|c|}{ WBC } \\
\hline & \multicolumn{3}{|c|}{ Quartile 1} & \multicolumn{3}{|c|}{ Quartile 2 } & \multicolumn{3}{|c|}{ Quartile 3} & \multicolumn{3}{|c|}{ Quartile 4} \\
\hline & $\mathrm{HR}$ & $95 \% \mathrm{Cl}$ & $\mathrm{P}$ & HR & $95 \% \mathrm{Cl}$ & $\mathrm{P}$ & $\mathrm{HR}$ & $95 \% \mathrm{Cl}$ & $\mathrm{P}$ & HR & $95 \% \mathrm{Cl}$ & $\mathrm{P}$ \\
\hline Anadjusted & 1 & - & - & 1.77 & $0.58-5.40$ & 0.3185 & 3.86 & $1.44-10.33$ & 0.0073 & 6.79 & $2.58-17.83$ & 0.0001 \\
\hline Adjusted for demographics & 1 & - & - & 1.71 & $0.56-5.23$ & 0.3493 & 1.71 & $0.56-5.23$ & 0.0106 & 3.65 & $1.35-9.84$ & $<0.0001$ \\
\hline $\begin{array}{l}\text { Adjusted for demographics } \\
\text { and risk factors }\end{array}$ & 1 & - & - & 1.58 & $0.51-4.92$ & 0.4263 & 3.81 & $1.39-10.43$ & 0.0091 & 7.01 & $2.65-18.55$ & $<0.0001$ \\
\hline $\begin{array}{l}\text { Adjusted for above and sICH } \\
\text { severity" }\end{array}$ & 1 & - & - & 0.61 & $0.18-2.05$ & 0.4218 & 1.74 & $0.62-4.91$ & 0.2922 & 1.31 & $0.44-3.86$ & 0.6275 \\
\hline \multirow[t]{2}{*}{$\begin{array}{l}\text { Adjusted for above and CRP } \\
\text { quartiles }\end{array}$} & 1 & - & - & 0.67 & $0.20-2.26$ & 0.5201 & 2.18 & $0.76-6.21$ & 0.1464 & 1.23 & $0.41-3.68$ & 0.7079 \\
\hline & \multicolumn{12}{|c|}{ CRP } \\
\hline Outcome event & HR & $(95 \% \mathrm{Cl})$ & $P$ & HR & $(95 \% \mathrm{Cl})$ & $P$ & HR & $(95 \% \mathrm{Cl})$ & $P$ & $\mathrm{HR}$ & $(95 \% \mathrm{Cl})$ & $P$ \\
\hline Anadjusted & 1 & - & - & 1.39 & $0.61-3.17$ & 0.4380 & 1.61 & $0.71-3.64$ & 0.2543 & 1.59 & $0.70-3.60$ & 0.2658 \\
\hline Adjusted for demographics & 1 & - & - & 1.36 & $0.59-3.12$ & 0.4694 & 1.66 & $0.73-3.76$ & 0.2276 & 1.59 & $0.70-3.59$ & 0.2694 \\
\hline $\begin{array}{l}\text { Adjusted for demographics } \\
\text { and risk factors }\end{array}$ & 1 & - & - & 1.25 & $0.54-2.87$ & 0.6060 & 1.48 & $0.64-3.40$ & 0.3550 & 1.46 & $0.64-3.34$ & 0.3659 \\
\hline $\begin{array}{l}\text { Adjusted for above and sICH } \\
\text { severity" }\end{array}$ & 1 & - & - & 1.48 & $0.63-3.48$ & 0.3661 & 1.10 & $0.46-2.66$ & 0.8280 & 2.33 & $0.97-5.56$ & 0.0572 \\
\hline $\begin{array}{l}\text { Adjusted for above and } \\
\text { WBC count quartiles }\end{array}$ & 1 & - & - & 1.90 & $0.78-4.64$ & 0.1604 & 1.44 & 0.59-3.55 & 0.4239 & 2.83 & 1.14-7.05 & 0.0254 \\
\hline
\end{tabular}

$\mathrm{Cl}$ indicates confidence intervals; $\mathrm{HR}$, Hazard ratio, $\mathrm{sICH}$, spontaneous intracerebral hemorrhage, WBC, white blood cells, $\mathrm{CRP}$, C-reactive protein, olCH, Hemphill's $\mathrm{ICH}$ score. Legend for table: Demographics: age (per 10-year increase) and sex. Risk factors: arterial hypertension, diabetes mellitus, glucose concentration (per 1.0 $\mathrm{mmol} / \mathrm{l}$ increase) at admission, smoking status and alcohol abuse. sICH severity: olCH scores (per 1-point increase) and sICH hematoma volume (per $1 \mathrm{cc}$ increase) "This model included interaction terms between smoking status and diabetes mellitus, and between diabetes mellitus and glucose concentration at admission, to satisfy This model included interaction terms between smoking status and diabetes melitus, and between diabetes mellitus and glucose concentration at admission, to satisfy

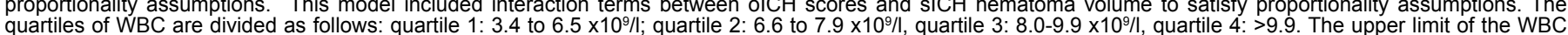
measurement was $21.0 \times 10^{9} / \mathrm{l}$. The quartiles of CRP are divided as follows: quartile 1: 0.8 to $5 \mathrm{mg} / \mathrm{l}$; quartile 2: 5.1 to $9.0 \mathrm{mg} / \mathrm{l}$, quartile $3: 9.1$ to 17.1 , quartile $4: 17.1 \mathrm{mg} / \mathrm{l}$ measurement was $21.0 \times 10^{9} /$. The quartiles of CRP are divided as
or greater. The upper limit of the CRP measurement was $96 \mathrm{mg} / \mathrm{l}$.

Table 3: Unadjasted and udjusted hazard ratios (HR) for the association between WBC count and CRP concentration at admission with 30-day mortality from any causes after $\mathrm{sICH}$, stratified by quartile of each marker.

\begin{tabular}{|c|c|c|c|c|c|}
\hline \multirow{2}{*}{ sICH Volume } & \multicolumn{4}{|c|}{ 30-day Mortality Rate by WBC quartiles } & \multirow[b]{2}{*}{$\mathrm{P}$ Value } \\
\hline & Quartile 1 & Quartile 2 & Quartile 3 & Quartile 4 & \\
\hline$<25 \mathrm{~mm}^{3}$ & $\begin{array}{c}2.63 \\
(1 / 38)\end{array}$ & $\begin{array}{l}11.54 \\
(3 / 26)\end{array}$ & $\begin{array}{l}20.00 \\
(7 / 35)\end{array}$ & $\begin{array}{l}41.67 \\
(5 / 12)\end{array}$ & 0.0057 \\
\hline $25-50 \mathrm{~mm}^{3}$ & $\begin{array}{c}33.33 \\
(2 / 6)\end{array}$ & $\begin{array}{l}27.27 \\
(3 / 11)\end{array}$ & $\begin{array}{l}57.14 \\
(4 / 7)\end{array}$ & $\begin{array}{c}71.43 \\
(10 / 14)\end{array}$ & 0.0577 \\
\hline $51-80 \mathrm{~mm}^{3}$ & $\begin{array}{c}100.00 \\
(1 / 1)\end{array}$ & $\begin{array}{c}50.00 \\
(1 / 2)\end{array}$ & $\begin{array}{l}80.00 \\
(4 / 5)\end{array}$ & $\begin{array}{l}80.00 \\
(4 / 5)\end{array}$ & 0.7602 \\
\hline$>80 \mathrm{~mm}^{3}$ & $\begin{array}{c}33.33 \\
(1 / 3)\end{array}$ & $\begin{array}{c}100.00 \\
(1 / 1)\end{array}$ & $\begin{array}{c}100.00 \\
(4 / 4)\end{array}$ & $\begin{array}{c}100.00 \\
(5 / 5)\end{array}$ & 0.0486 \\
\hline \multirow{2}{*}{ sICH Volume } & \multicolumn{4}{|c|}{ 30-day Mortality Rate by CRP quartiles } & \\
\hline & Quartile 1 & Quartile 2 & Quartile 3 & Quartile 4 & $\mathrm{P}$ Value \\
\hline$<25 \mathrm{~mm}^{3}$ & $\begin{array}{l}10.34 \\
(3 / 29)\end{array}$ & $\begin{array}{l}33.33 \\
(4 / 12)\end{array}$ & $\begin{array}{c}66.67 \\
(2 / 3)\end{array}$ & $\begin{array}{c}- \\
(0 / 0)\end{array}$ & 1.0000 \\
\hline $25-50 \mathrm{~mm}^{3}$ & $\begin{array}{l}12.90 \\
(4 / 31)\end{array}$ & $\begin{array}{c}44.44 \\
(4 / 9)\end{array}$ & $\begin{array}{c}100.00 \\
(6 / 6)\end{array}$ & $\begin{array}{c}100.00 \\
(1 / 1)\end{array}$ & 0.0001 \\
\hline $51-80 \mathrm{~mm}^{3}$ & $\begin{array}{c}9.52 \\
(2 / 21)\end{array}$ & $\begin{array}{l}64.29 \\
(9 / 14)\end{array}$ & $\begin{array}{l}50.00 \\
(1 / 2)\end{array}$ & $\begin{array}{c}100.00 \\
(4 / 4)\end{array}$ & 0.0005 \\
\hline$>80 \mathrm{~mm}^{3}$ & $\begin{array}{l}23.33 \\
(7 / 30)\end{array}$ & $\begin{array}{l}66.67 \\
(2 / 3)\end{array}$ & $\begin{array}{l}50.00 \\
(1 / 2)\end{array}$ & $\begin{array}{c}75.00 \\
(6 / 8)\end{array}$ & 0.0348 \\
\hline
\end{tabular}

CRP indicates C-reactive protein, ICH, intracerebral hemorrhage. White blood cell (WBC) count values are $\times 10^{9} / \mathrm{I}$. The quartiles of WBC are divided as follows: quartile $1: 3.4$ to $6.5 \times 10^{9} /$; quartile $2: 6.6$ to $7.9 \times 10^{9} / l$, quartile $3: 8.0-9.9 \times 10^{9} / \mathrm{l}$, quartile $4:>9.9$. The upper limit of the WBC measurement was $21.0 \times 10^{9} / \mathrm{l}$. The quartiles of CRP are divided as follows: quartile 1: 0.8 to $5 \mathrm{mg} / \mathrm{l}$; quartile $2: 5.1$ to $9.0 \mathrm{mg} / \mathrm{l}$, quartile $3: 9.1$ to 17.1 , quartile $4: 17.1 \mathrm{mg} / \mathrm{l}$ or greater. The upper limit of the CRP measurement was $96 \mathrm{mg} / \mathrm{l}$.

Table 4: ICH volume and 30-day Mortality stratified by WBC Count and CRP concentration quartiles

\begin{tabular}{|c|c|c|c|c|c|}
\hline \multirow{2}{*}{ CRP Level } & \multicolumn{4}{|c|}{ 30-day Mortality Rate by WBC Quartiles } & \multirow[b]{2}{*}{$\mathrm{P}$ Value } \\
\hline & Quartile 1 & Quartile 2 & Quartile 3 & Quartile 4 & \\
\hline $\mathrm{CRP} \leq 15 \mathrm{mg} / \mathrm{l}$ & $\begin{array}{c}5.71 \\
(2 / 35)\end{array}$ & $\begin{array}{l}25.81 \\
(8 / 31)\end{array}$ & $\begin{array}{c}30.77 \\
(12 / 39)\end{array}$ & $\begin{array}{c}68.00 \\
(17 / 25)\end{array}$ & $<0.0001$ \\
\hline CRP $>15$ mg/dl & $\begin{array}{l}23.08 \\
(3 / 13)\end{array}$ & $\begin{array}{c}- \\
(0 / 9)\end{array}$ & $\begin{array}{l}58.33 \\
(7 / 12)\end{array}$ & $\begin{array}{l}63.64 \\
(7 / 11)\end{array}$ & 0.0076 \\
\hline
\end{tabular}

CRP indicates C-reactive protein. White blood cell (WBC) count values are $\times 10^{9} / \mathrm{l}$. The quartiles of WBC are divided as follows: quartile $1: 3.4$ to $6.5 \times 10^{9} / /$; quartile $2: 6.6$ to $7.9 \times 10^{9} /$, quartile $3: 8.0-9.9 \times 10^{9} / l$, quartile $4:>9.9$. The upper limit of the WBC measurement was $21.0 \times 10^{9} / 1$

Table 5: WBC Count, CRP, and 30-day Mortality.

The same analyses were conducted to predict the better 30 day functional outcome. Both WBC count and CRP concentration at admission showed not evident predictive effects on 30-day functional outcome. Only olCH score remained an independent predictor of better 30-day functional outcome in the full multivariable model (adjusted HR per point increase $0.41,95 \% \mathrm{CI} 0.31-0.54, \mathrm{P}<0.0001$ ).

\section{Discussion}

The role of inflammation in the physiopathology of $\mathrm{sICH}$ is becoming increasingly well recognized [7]. Previous clinical studies have provided evidence that supports the role of leukocytes in sICH. An elevated WBC count was associated with hematoma size $[31,32]$. Predicted early neurologic deterioration, worse outcome and mortality after sICH $[12,14,30,31]$.

The present study offers several important insights. An inflammatory response is often found at the site of intracerebral hematoma in both human and animal ICH models [33-35]. There is some evidence to suggest that inflammation and the WBC itself 
may directly contribute to sICH injury [7]. Leukocytes can promote inflammatory tissue injury indirectly by stimulating macrophages to release pro-inflammatory mediators [36] and via the effects of oxygen-free radicals and complement activation [9]. Our data support these potential pathobiologic processes, as patients with higher WBC counts had greater hematoma volume at admission. Thus, WBC count may be both a marker of a heightened inflammatory state and a direct contributor to hematoma growth and brain injury in the setting of sICH.

In the present study, we observed strong relationships among baseline inflammatory markers (WBC count and CRP concentration) and mortality. These observations are in agreement not only with previous studies of WBC count $[12,14,31,32]$. But also with studies of other inflammatory markers $[9,10,13,37]$. The basis for this remains unknown, but the early divergence of the cumulative mortality curves suggests that patients with an elevated WBC count have a higher risk of death from the index event. This early hazard may be related the possibility that the degree of WBC elevation reflects the severity of the sICH. This hypothesis was supported by our data, in which there were strict correlations between WBC count and both hematoma volume at admission and sICH severity. Moreover, after adjustment for possible confounding factors the association between WBC count and outcome was greatly attenuated and not more significant. From this point of view, WBC count represents an early biological marker of sICH severity. An important advantage of the WBC count as a predictor of sICH severity and clinical outcomes is its ubiquity. A WBC count is available in every hospital and as part of the complete blood count, is it almost universally assayed in all patients presenting with sICH. The value for the highest quartile of WBC count in our study was $>9.9 \times 10^{9} /$, which is close to the upper limit of normal for many laboratories. Vascular-specific anti-inflammatory and antileukocyte therapies are developed as an alternative or adjunctive therapeutic approach to $\mathrm{sICH},[7]$ an elevated WBC count may help identify patients who would benefit the most from these interventions. Furthermore, the attenuated relationship between WBC count and mortality in patients who underwent surgery is intriguing and may be related to the anti-inflammatory effect of removing intracerebral hematoma and hence importance of hematoma evacuation in patients with an elevated WBC count. This hypothesis would need to be prospectively tested in randomized trials with serial measurements of inflammatory markers.

To our knowledge, this is the first study to look at both CRP and WBC counts in sICH patients. CRP concentration at admission was able to demostrate only a marginal association $(\mathrm{P}=0.0747)$ with 30-day mortality, probably due to a very early determination (120 minutes) after sICH onset. The relationship between inflammatory marker status and 30-day mortality became significant after adjustment for potential confounders including age, gender, risk factors, sICH severity and WBC count. It is conceivable that an increased CRP concentration after sICH onset is due to inflammation related to the pathophysiology of intracerebral hematoma growth and might reflect the extent of the hematoma volume and not to a pre-existent subclinical inflammatory status. Experimental data demonstrate that the acute phase response to intracerebral hematoma occurred later when compared to ischemic stroke [38]. IL-6, a proinflammatory cytokine that regulate at the level of transcription CRP concentrations [39]. were observed in blood, cerebrospinal fluid, or brain extracts at $1 \mathrm{~h}$ after experimental $\mathrm{ICH}$ [38].The limitated data available regarding the time course of acute phase responses in humans showed a more delayed response $[7,10,11]$. This may suggest that only serial
CRP measurements after symptom onset might help to identify those patients who are predisposed to an intensive activation of the inflammatory system. We hypothesize that the measurement of CRP concentrations later after sICH onset and not at admission could be the best marker to estimate these individual reactions of the inflammatory system. However, the significant independent association between inflammatory status and outcome may suggest that the inflammatory system reacts more intensely in some patients and may explain the individual differences in inflammatory response to intracerebral hematoma and the independence in regard to sICH volumes in the acute phase. We found that patients with an elevated CRP concentration had a relatively high risk of dying at 30day $(23.1 \%$ to $63.6 \%)$ that increase progressively across WBC count strata. Furthermore, among patients with a low WBC count, 30-day mortality was related to baseline CRP concentration: patients had a low mortality rate $(5.7 \%)$ if they had a low CRP concentration and intermediate mortality rates (23.1\% to $58.3 \%$ ) if they had higher CRP levels (Table 5). Thus, the combined use of baseline WBC count and CRP concentration can be used to substratify mortality risk and identify patients with very low versus intermediate 30-day mortality. At the same time, WBC and CRP appears to be suitable to substratify mortality risk in patients with different volume of the hematoma a measure that correlates well with the outcome and is a very useful indicator for surgery, $[30]$ in a different and complementary way. This aspect is very intriguing and deserves further studies.

There are several limitations to the present study. As an observational investigation, it can only identify associations and not causality. We did not collect information on WBC differential, which may be important. The relationship between CRP and prognosis must be considered exploratory.

In conclusion, in patients with sICH, elevations in a simple, widely available blood test, the WBC count, were associated with 30-day high mortality rates although, this association reversed when other counfounding variables are taken in account suggesting only a role of surrogate biomarker of sICH severity. CRP concentrations appear more effective in predicting prognosis although at the moment a too early dosing can limit its predictive power. No significant predictive role for both markers was found for 30-day functional outcome. It is plausible that after further analyses CRP concentrations could be used to stratify patients across a gradation of 30-day mortality risk in sICH patients.

\section{References}

1. Broderick JP, Brott T, Tomsick T, Miller R, Huster G ( 1993) Intracerebra hemorrhage more than twice as common as subarachnoid hemorrhage. J Neurosurg 78: 188-191.

2. Broderick JP, Adams HP Jr, Barsan W, Feinberg W, Feldmann E, et al. ( 1999) Guidelines for the management of spontaneous intracerebral hemorrhage: A statement for healthcare professionals from a special writing group of the Stroke Council, American Heart Association. Stroke 30: 905-915.

3. Dennis MS (2003) Outcome after brain haemorrhage. Cerebrovasc Dis 16 Suppl 1: 9-13.

4. Mendelow AD, Gregson BA, Fernandes HM, Murray GD, Teasdale GM, et al. (2005) Early surgery versus initial conservative treatment in patients with spontaneous supratentorial intracerebral haematomas in the International Surgical Trial in Intracerebral Haemorrhage (STICH): a randomised trial Lancet 365: 387-397.

5. Mayer SA (2003) Ultra-early hemostatic therapy for intracerebral hemorrhage Stroke 34: 224-229.

6. Aronowski J, Hall CE (2005) New horizons for primary intracerebral hemorrhage treatment: experience from preclinical studies. Neurol Res 27: 268-279. 
Citation: Godoy DA, Papa F, Campi V, del Valle M, Piñero G, et al. (2010) Relationship between Baseline White Blood Cell and C-Reactive Protein with Mortality in Patients with Spontaneous Intracerebral Hemorrhage. J Neurol Neurophysiol 1:104. doi:10.4172/2155-9562.1000104

Page 8 of 8

7. Wang J, Dore S (2007) Inflammation after intracerebral hemorrhage. J Cereb Blood Flow Metab 27: 894-908.

8. Gong C, Hoff JT, Keep RF (2000) Acute inflammatory reaction following experimental intracerebral hemorrhage in rat. Brain Res 871: 57-65.

9. Keep RF, Xi G, Hua Y, Hoff JT (2005) The deleterious or beneficial effects of different agents in intracerebral hemorrhage: think big, think small, or is hematoma size important? Stroke 36: 1594-1596.

10. Castillo J, Davalos A, Alvarez-Sabin J, Pumar JM, Leira R, et al. (2002) Molecular signatures of brain injury after intracerebral hemorrhage. Neurology 58: $624-629$

11. Silva Y, Leira R, Tejada J, Lainez JM, Castillo J, et al. (2005) Molecular signatures of vascular injury are associated with early growth of intracerebral hemorrhage. Stroke 36: 86-91.

12. Leira R, Davalos A, Silva Y, Gil-Peralta A, Tejada J (2004) Early neurologic deterioration in intracerebral hemorrhage: predictors and associated factors. Neurology 63: 461-467

13. Leira R, Castellanos M, Alvarez-Sabin J, Diez-Tejedor E, Davalos A, et al (2005) Headache in cerebral hemorrhage is associated with inflammatory markers and higher residual cavity. Headache 45: 1236-1243.

14. Castellanos M, Leira R, Tejada J, Gil-Peralta A, Davalos A, et al. (2005) Predictors of good outcome in medium to large spontaneous supratentorial intracerebral haemorrhages. J Neurol Neurosurg Psychiatry 76: 691-695.

15. Di Napoli M, Schwaninger M, Cappelli R, Ceccarelli E, Di Gianfilippo G, et al (2005) Evaluation of C-reactive protein measurement for assessing the risk and prognosis in ischemic stroke: a statement for health care professionals from the CRP Pooling Project members. Stroke 36: 1316-1329.

16. Canova CR, Courtin C, Reinhart WH (1999) C-reactive protein (CRP) in cerebro-vascular events. Atherosclerosis 147: 49-53.

17. Godoy DA, Pinero G, Di Napoli M (2006) Predicting mortality in spontaneous intracerebral hemorrhage: can modification to original score improve the prediction? Stroke 37: 1038-1044.

18. Steiner T, Kaste M, Forsting M, Mendelow D, Kwiecinski H, et al. (2006) Recommendations for the management of intracranial haemorrhage - part I: spontaneous intracerebral haemorrhage. The European Stroke Initiative Writing Committee and the Writing Committee for the EUSI Executive Committee. Cerebrovasc Dis 22: 294-316.

19. Teasdale G, Jennett B (1974) Assessment of coma and impaired consciousness. A practical scale. Lancet 2: 81-84

20. Knaus WA, Draper EA, Wagner DP, Zimmerman JE (1985) APACHE II: a severity of disease classification system. Crit Care Med 13: 818-829.

21. Hemphill JC 3rd, Bonovich DC, Besmertis L, Manley GT, Johnston SC (2001) The ICH score: a simple, reliable grading scale for intracerebral hemorrhage. Stroke 32: 891-897.

22. Di Napoli M, Papa F, Bocola V (2001) C-reactive protein in ischemic stroke: an independent prognostic factor. Stroke 32: 917-924.
23. Di Napoli M, Papa F, Bocola V (2001) Prognostic influence of increased C-reactive protein and fibrinogen levels in ischemic stroke. Stroke 32: 133-138.

24. Kothari RU, Brott T, Broderick JP, Barsan WG, Sauerbeck LR, et al. (1996) The $A B C s$ of measuring intracerebral hemorrhage volumes. Stroke 27: 1304-1305.

25. Cheung RT, Zou LY (2003) Use of the original, modified, or new intracerebra hemorrhage score to predict mortality and morbidity after intracerebra hemorrhage. Stroke 34: 1717-1722.

26. Graeb DA, Robertson WD, Lapointe JS, Nugent RA, Harrison PB (1982) Computed tomographic diagnosis of intraventricular hemorrhage. Etiology and prognosis. Radiology 143: 91-96.

27. Diringer MN, Edwards DF, Zazulia AR (1998) Hydrocephalus: a previously unrecognized predictor of poor outcome from supratentorial intracerebral hemorrhage. Stroke 29: 1352-1357.

28. Teasdale G, Jennett B (1974)Assessment of coma and impaired consciousness. A practical scale. Lancet 2: 81-84

29. Godoy DA, Pinero GR, Svampa S, Papa F, Di Napoli M (2008) Hyperglycemia and Short-term Outcome in Patients with Spontaneous Intracerebra Hemorrhage. Neurocrit Care 9: 217-229.

30. Maiuri F, Corriero G, Passarelli F, Cirillo S, Astarita G (1990) CT indications for surgery and evaluation of prognosis in patients with spontaneous intracerebral haematomas. Br J Neurosurg 4: 155-60.

31. Bestue-Cardiel M, Martin-Martinez J, Iturriaga-Heras C, Ara-Callizo JR Oliveros-Juste A (1999) Leukocytes and primary intracerebral hemorrhage. Rev Neurol 29: 968-971.

32. Suzuki S, Kelley RE, Dandapani BK, Reyes-Iglesias Y, Dietrich WD, et al (1995) Acute leukocyte and temperature response in hypertensive intracerebra hemorrhage. Stroke 26: 1020-1023.

33. Power C, Henry S, Del Bigio MR, Larsen PH, Corbett D, et al. (2003) Intracerebral hemorrhage induces macrophage activation and matrix metalloproteinases. Ann Neurol 53: 731-742.

34. Wasserman JK, Zhu X, Schlichter LC (2007) Evolution of the inflammatory response in the brain following intracerebral hemorrhage and effects of delayed minocycline treatment. Brain Res. 1180: 140-154.

35. Mackenzie JM, Clayton JA (1999) Early cellular events in the penumbra of human spontaneous intracerebral hemorrhage. J Stroke Cerebrovasc Dis 8: 1-8.

36. Sinn DI, Lee ST, Chu K, Jung KH, Kim EH, et al. (2007) Proteasomal inhibition in intracerebral hemorrhage: neuroprotective and anti-inflammatory effects of bortezomib. Neurosci Res 58: 12-18.

37. Abilleira S, Montaner J, Molina CA, Monasterio J, Castillo J, et al. (2003) Matrix metalloproteinase- 9 concentration after spontaneous intracerebral hemorrhage. J Neurosurg 99: 65-70.

38. Qureshi Al, Suri MF, Ling GS, Khan J, Guterman LR, et al.(2001) Absence of early proinflammatory cytokine expression in experimental intracerebral hemorrhage. Neurosurgery 49: 416-420.

39. Pepys MB, Hirschfield GM ( 2003) C-reactive protein: a critical update. J Clin Invest 111: 1805-1812. 